\title{
Electromagnetic navigation reduces radiation exposure for retrograde drilling in osteochondrosis dissecans of the talus
}

Oliver D Jungesblut ${ }^{1,2+}$, Josephine Berger-Groch ${ }^{2 *}$ D, Michael Hoffmann $^{3}$, Malte Schroeder ${ }^{2}$, Kara L. Krajewski ${ }^{1}$, Ralf Stuecker ${ }^{1,2}$ and Martin Rupprecht ${ }^{1,2}$

\begin{abstract}
Background: Retrograde drilling in osteochondrosis dissecans (OCD) is a widely used surgical intervention. A radiation-free electromagnetic navigation system (ENS)-based method was compared with the standard freehand fluoroscopic (SFF) method regarding clinical applicability.

Methods: We performed a clinical cohort study at a department of Orthopaedics in a Level 1 children's hospital with 40 patients (20 SFF and 20 ENS). Retrograde drilling of the talar dome was used in patients with unstable medial OCD (MRI stage 2 according to Hepple's revised classification; stage 2 according to the International Cartilage Repair Society). The outcome measurements were: (a) Intraoperative fluoroscopy exposure and length of surgery and (b) Postoperative serial follow-up MRIs every 6 months.

Results: 22 female and 18 male patients aged $13.8 \pm 1.6$ years (range: 11-17 years) were included. Using the ENS technique, length of surgery was significantly reduced to $20.2 \pm 6.4$ min compared to $36.1 \pm 11.8 \mathrm{~min}(p<0.01)$ for the SFF technique. The average $x$-ray radiation time for the SFF technique was $23.5 \pm 13.5 \mathrm{sec}$ and $1.9 \pm 1.7 \mathrm{sec}$ for the ENS technique $(p<0.01)$. Radiation exposure was significantly reduced from $44.6 \pm 19.7 \mathrm{mSV}$ (SFF technique) to $5.6 \pm 2.8 \mathrm{mSV}$ (ENS technique) $(p<0.01)$. Intraoperative perforation of cartilage occurred once in the SFF group. Correct placement of the drilling channel was verified in all patients on follow-up MRI after six months and a timely healing was seen after two years.
\end{abstract}

Conclusions: The ENS method provides for a significant reduction in length of surgery and radiation exposure. ENS was without intraoperative cartilage perforation. The clinical and radiological follow-up parameters are comparable for SFF- and ENS-guided retrograde drilling.

Trial registration: WF - 085/20, 05/2020 "retrospectively registered" https://www.aerztekammer-hamburg.org/ ethik_kommission.html.

Keywords: Electromagnetic navigation, Talus, Retrograde drilling, Osteochondritis dissecans, adolescent, cartilage

\footnotetext{
* Correspondence: josi.berger@gmail.com

${ }^{\dagger}$ Oliver D Jungesblut and Josephine Berger-Groch contributed equally to this

study.

Oliver D Jungesblut and Josephine Berger-Groch share first authorship.

${ }^{2}$ Department of Trauma and Orthopaedic Surgery, University Medical Center Hamburg-Eppendorf, Martinistr. 52, 20246 Hamburg, Germany

Full list of author information is available at the end of the article
}

(c) The Author(s). 2021 Open Access This article is licensed under a Creative Commons Attribution 4.0 International License, which permits use, sharing, adaptation, distribution and reproduction in any medium or format, as long as you give appropriate credit to the original author(s) and the source, provide a link to the Creative Commons licence, and indicate if changes were made. The images or other third party material in this article are included in the article's Creative Commons licence, unless indicated otherwise in a credit line to the material. If material is not included in the article's Creative Commons licence and your intended use is not permitted by statutory regulation or exceeds the permitted use, you will need to obtain permission directly from the copyright holder. To view a copy of this licence, visit http://creativecommons.org/licenses/by/4.0/. The Creative Commons Public Domain Dedication waiver (http://creativecommons.org/publicdomain/zero/1.0/) applies to the data made available in this article, unless otherwise stated in a credit line to the data. 


\section{Background}

Increasing participation of children in competitive sports with intensive training [1] as well as increasing obesity in childhood [2], both risk factors for osteochondrosis dissecans (OCD) of the talus, in addition to an ever-increasing use of MRI imaging [3] have led to an increase in the incidence of talar OCD. There is a peak in patients between 12 and 19 years of age [4]. The therapy of talar OCD is challenging and a variety of conservative and surgical methods exist [5]. In contrast to adults, spontaneous healing of talar OCD has been documented in children [6]. In stable OCD, non-surgical treatment includes abstinence of certain sports and compression loads as well as adjustment of vitamin D levels [7, 8]. An efficient and commonly employed surgical therapy of nearly unstable OCD is arthroscopically-assisted drilling for subchondral decompression and revascularization [9-13].

Retrograde drilling avoids articular surface violation in most cases, but control of the drill depth and drill placement can be challenging and require radiographic guidance [14]. As a result of the complexity of these surgeries, numerous approaches have been reported: freehand fluoroscopy-guided drilling with or without guiding techniques [15] such as computed tomography $[16,17]$, MRI $[18,19]$ and ultrasound-guided [20] options, as well as opto-electronically [21] and x-ray [22] guidance.

The aim of this study was thus to compare a novel electromagnetic navigation system (ENS)-based technique with the standard freehand fluoroscopically guided procedure in patients with talar OCD. The precision of the drilling with the ENS method was well documented in previous cadaver studies. [16, 23-25] We hypothesized, that (I) the length of operation, (II) the radiation exposure, and (III) the number of intra-operative complications, are reduced with the ENS-technique.

\section{Methods}

In this clinical cohort study, 40 patients were included from March 2014 to October 2016. Inclusion criteria were: (I) the presence of an atraumatic medial lesion in MRI (stage 2 according to Hepple et al. [26] and stage 2 according to the International Cartilage Repair Society [27]), (II) a history of pain for a minimum of six months, (III) age under 18 years at initial presentation, and (IV) written consent by the parents. Patients with previous surgery, lateral lesions, posttraumatic lesions, or those requiring arthrotomy and surgical refixation were excluded. The patients included were alternately treated with either the standard free-hand fluoroscopic (SFF) or the ENS technique. Both techniques were executed only by two senior surgeons with the same level of experience in both techniques. Every surgeon treated half of the children via ENS and half of the children via the SFF technique.

\section{Operative techniques}

In both techniques, a standard arthroscopy of the upper ankle joint was performed. The OCD lesion was identified on the medial talar dome and intra-operative fluoroscopy (Ziehm imaging GmbH, Nürnberg, Germany, type Ziehm Solo) and the indication for retrograde drilling was confirmed in all cases. The indication for retrograde drilling was given when overlying cartilage was seen to be intact during arthroscopy (stage 2 according to the ICRS-OD classification [28]).

\section{Retrograde drilling via standard freehand fluoroscopical guidance (SFF- method)}

A $1.6 \mathrm{~mm}$ guide-wire was advanced through the distal lateral side of the talar cortex into the OCD using pulsed fluoroscopical guidance in antero-posterior and lateral views. Once the surgeons identified a distance of $2 \mathrm{~mm}$ to the joint line, the procedure ended. The final K-wire position was fluoroscopically documented in two planes. Three K-wires were positioned and finally the drilling was executed with a cannulated $2.9 \mathrm{~mm}$ drill above all three K-wires. At the end of operation, the cartilage surface was checked for perforation via arthroscopy.

\section{Retrograde drilling via electromagnetical guidance (ENS- method)}

The NaviDrill electromagnetic targeting device was implemented in this study (NaviDrill ${ }^{\mathrm{Tu}}$, Arthrex Inc., Naples, FL, USA). Using electromagnetic tracking data obtained intraoperatively, the system provides realtime information on operative instrument placement displayed on a monitor (Fig. 1a). A special probe hook of small size was constructed for ankle joint arthroscopy (Fig. 1b). The drill sleeve contains the electromagnetic field generator. An electromagnetic sensor is implemented into the tip of the probe hook and calibrated once during the fabrication process (Fig. 1c and d). Spatiotemporal referencing is gained from the sensor within the electromagnetic field provided by the drill sleeve. The correct angle and direction are ensured by a continuous visual real-time feedback of the drill position. Pre- or intra-operative calibrations as well as patient reference bases are not required.

For this procedure, the probe hook was placed in three different positions within the area of the OCD. The position of the probe hook was continuously monitored via arthroscopy. Similar to the free-hand fluoroscopically assisted technique, a skin incision was made with subsequent blunt preparation to the bone cortex of the talus. 


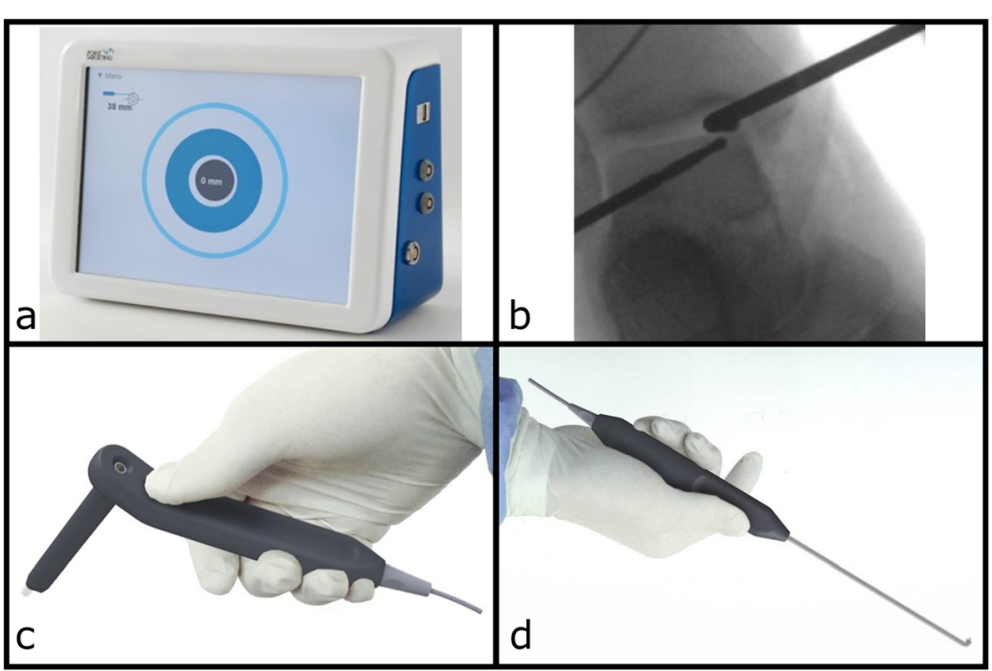

Fig. 1 a/b/c/d Intraoperative equipment: aMonitor. $\mathbf{b}$ Intraoperative $x$-ray. c Drill sleeve. $\mathbf{d}$ Probe hook

A $1.6 \mathrm{~mm}$ K-wire was passed through a central slot in the electromagnetic field generator (Fig. 2).

The entry point was chosen about $2 \mathrm{~cm}$ distal of the lateral standard arthroscopy portal. Subsequent a onetime control by fluoroscopy was performed to preserve the lateral gutter. Additionally, the final position of the k-wire was documented fluoroscopically.

Drilling depth was derived from the information provided on the distance between the tip of the probe hook and the drill sleeve as visualized on the monitor. A stop mark was set on the $\mathrm{K}$-wire using a marker pen (indicated distance minus $2 \mathrm{~mm}$ to avoid penetrating cartilage) in line with the drilling depth. Real-time drilling direction was provided on the monitor during navigation and allowed for adjustments. As soon as the stop mark on the K-wire was reached, drilling was stopped. After positioning three K-wires, the drilling was executed with a $2.9 \mathrm{~mm}$ cannulated drill.

\section{Measurements}

We analyzed the radiation exposure and length of surgery for all cases. All 40 patients were seen in our outpatient clinic in a six months rhythm after surgery and underwent magnetic resonance imaging (MRI). Followup MRIs were performed in radiology clinics freely chosen by the patients according to our specifications. We required a minimum standard of a 1.5 Tesla MRI generating $3 \mathrm{~mm}$ fat suppressed layers (T2 coronar, sagittal, and transaxial). The MRIs were analyzed in a systematic and quantitative manner by two independent raters with regard to position, size, and development in

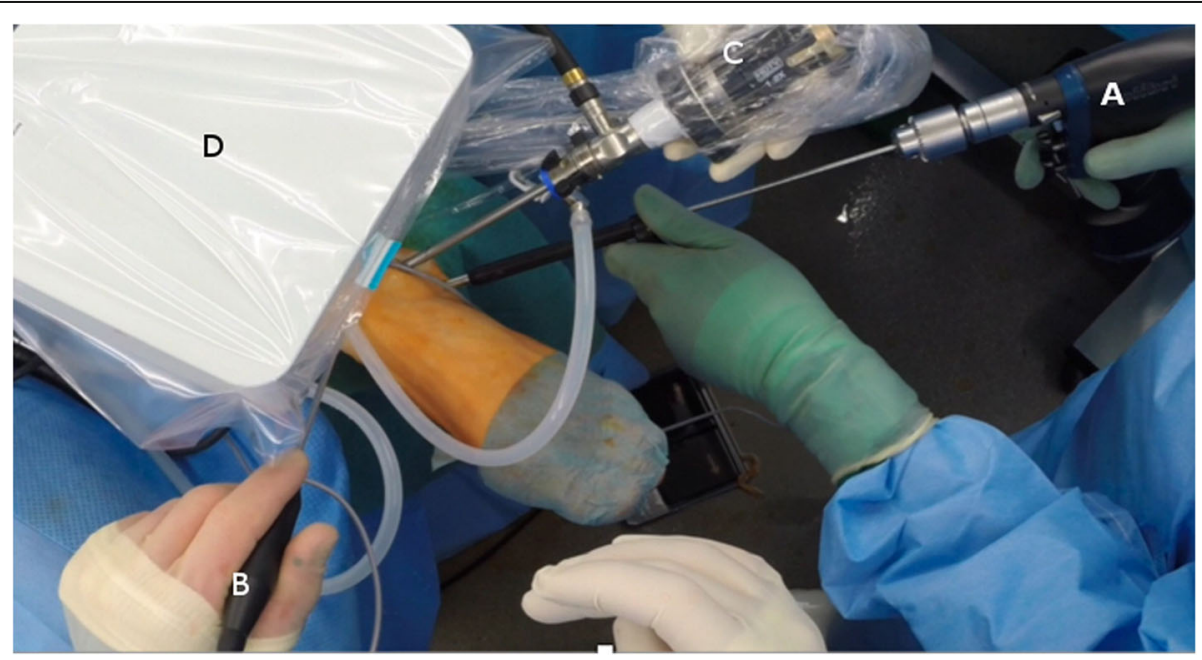

Fig. 2 Intraoperative setting; a Drill, b Probe hook, c Arthroscope, d x-ray 
sagittal (antero-posterior) and coronal plane (medio-lateral). Raters were not blinded to the diagnosis of OCD but to size and location of the OCD. Results were compared and differences measuring $1 \mathrm{~mm}$ were rated as equal. In case of differences of $\geq 1 \mathrm{~mm}$, the arithmetic mean of both measurements was chosen.

Range of motion and pain on visual analog scale (VAS) were also documented at outpatient visits.

\section{Statistical analyses}

Descriptive statistics were used to describe the basic characteristics of the data set. Continuous variables were presented as a mean and standard deviation (SD). Differences between groups were calculated using the MannWhitney-U-Test. A $p$-value $<0.05$ was considered statistically significant. Statistical analyses were performed using SPSS statistical software (SPSS version 19.0, Chicago, IL, USA). We calculated Cohen's kappa coefficients with $95 \%$ confidence interval for all three classification systems. This acts as a measure of the level of agreement among the raters. A value of 1.0 means that there is a perfect agreement among the observers. A value of 0 suggests that the agreement was no better than chance alone. A value of less than 0 suggests greater than random disagreement [29].

\section{Results}

Twenty two female and 18 male patients aged $13.8 \pm 1.6$ years (range: $11-17$ years) were included in the study. 20 patients were treated by the ENS- and 20 patients were treated by the SFF method. The mean MRI size of OCD lesions for in the SFF technique group was $1.14 \pm$ $0.14 \mathrm{~cm}$ in the sagittal plane and $0.73 \pm 0.12 \mathrm{~cm}$ in the coronal plane. Patients undergoing the ENS technique had a lesion measuring $1.16 \pm 0.18 \mathrm{~cm}$ in the sagittal plane and $0.76 \pm 0.11 \mathrm{~cm}$ in the coronal plane on MRI (see Table 1$)$. No significant differences $(p>0.05)$ regarding size were detected. All lesions were localized on the medial shoulder of the talus. In the ENS technique group, length of surgery was $20.2 \pm 6.4$ min compared to $36.1 \pm 11.8 \mathrm{~min}$ in SFF technique group $(p<0.01)$.

The average $x$-ray radiation time in the SFF technique group was $23.5 \pm 13.5 \mathrm{sec}$ and $1.9 \pm 1.7 \mathrm{sec}$ in the ENS

Table 1 Data set

\begin{tabular}{lll}
\hline & SFF technique & ENS technique \\
\hline Age & $13.75 \pm 1.74$ & $13.6 \pm 1.67$ \\
Gender & 8 male, 12 female & 10 male, 10 female \\
Localization OCD tali & 10 right medial & 10 right medial \\
& 10 left medial & 10 left medial \\
OCD Size in MRI sagittal $(\mathrm{cm})$ & $1.14 \pm 0.14$ & $1.16 \pm 0.18$ \\
OCD Size in MRI coronar $(\mathrm{cm})$ & $0.73 \pm 0.12$ & $0.76 \pm 0.11$ \\
\hline
\end{tabular}

Table 2 Results

\begin{tabular}{llll}
\hline & SFF technique & ENS technique & $\boldsymbol{p}$-value \\
\hline Operation time (min) & $36.05 \pm 11.75$ & $20.15 \pm 6.42$ & $p<0.01$ \\
Radiation time (sec) & $23.05 \pm 13.53$ & $1.90 \pm 1.72$ & $p<0.01$ \\
Radiation exposure (mSv) & $44.58 \pm 19.68$ & $5.58 \pm 2.76$ & $p<0.01$ \\
Complications & 1 & 0 & \\
\hline
\end{tabular}

technique group $(p<0.01)$ Radiation exposure was thus reduced from $44.6 \pm 19.7 \mathrm{mSv}$ to $5.6 \pm 2.8 \mathrm{mSv}(p<0.01)$.

Perforation of cartilage occurred in one case in the SFF technique group (see Table 2).

Six months postoperatively, all patients presented in our outpatient clinic with current MRIs for follow-up. The average time of total follow-up was $30.0 \pm 4.3$ months. The follow-up MRI scans showed a steadily integration of the cartilage in all cases. The kappa value for interobserver reproducibility of size was 0.9 .

Two clinical cases are presented in Fig. $3(\mathrm{a} / \mathrm{b})$ and Fig. $4(\mathrm{a} / \mathrm{b})$.

Clinically, all patients manifested full range of motion in the affected tibiotalar joint six months postoperatively in comparison to the unaffected side and were pain-free $(\mathrm{VAS}=0)$ for activities of daily life. Swimming and cycling were possible in all cases, other sports were not permitted during the healing process.

\section{Discussion}

This study demonstrates the superiority of the ENS method compared to the standard fluoroscopic technique with respect to reduction of length of surgery and radiation exposure. For the ENS method, no relevant setup or calibration times are necessary. An extra-operative site for the positioning of a stationary-based reference point is also not necessary. In contrast to two-dimensional fluoroscopic imaging, no switching between planes is required, so that drilling procedures can be shortened and the cumulative $\mathrm{x}$-ray radiation exposure for both the patient and surgeon is significantly reduced [23].

Computer-assisted surgery for retrograde drilling procedures in OCD lesions has increased the precision of drilling $[18,19]$. Navigation systems offer higher precision compared with fluoroscopy-guided techniques; thus, different navigation techniques have been established, such as opto-electronic guidance systems [21], 3-dimensional fluoroscopy-based [22], MRI-based [18], or computed tomography-based methods [17]. Good results have been published with computer-assisted minimally invasive retrograde drilling [11]. Nevertheless, navigated procedures are time-consuming operations as the setup, image acquisition, registration and verification must be obtained [24]. Furthermore, reference base-related complications such as iatrogenic fractures, heterotopic ossifications and 


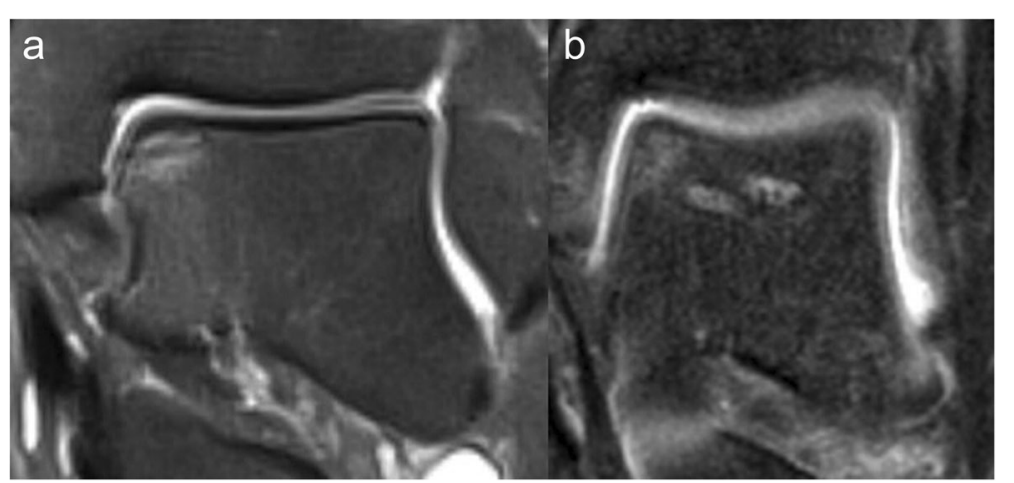

Fig. 3 a/b MRI 6 months postoperatively after standard procedure with visual drilling channels and 2 years postoperatively with good bone union

unintended dislocation of the reference base have been documented [30].

To avoid drilling of the hyaline cartilage and its concomitant damage, retrograde drilling close to the subchondral bone with preservation of the cartilage surface is the favorable technique [9]. However, the complex anatomy of the ankle makes retrograde drilling challenging. Frail bone structure after repetitive attempts to reach the OCD lesion can result in iatrogenic fractures $[25,31]$. Precise retrograde drilling without damaging the articular cartilage surface is thus very important [18, 32]. It is not always possible to use mechanical targeting devices, similar to those used for tunnel positioning in anterior cruciate ligament reconstruction [18], because their pre-shaped design does not always allow for accurate placement $[10,17]$.

In this study, an innovative ENS method with a small blunt probe hook, which serves as a dynamic target point, is presented. Additionally, a free choice of the starting point for the retrograde drilling with respect to important anatomic structures is possible, because the ENS method requires no pre-defined targeting angle to the tip of the probe hook.

Freehand fluoroscopy requires an average of approximately seven direction readjustments per operation, including backward drilling or even complete restarts [23]. Because real-time drilling direction information can be obtained on the monitor with the novel ENS method, readjustments of the drilling direction can be addressed concurrently within the drilling procedure. Regarding the drilling process time and radiation exposure, retrograde drilling with the ENS method required significant less operation time and radiation exposure. Furthermore, fluoroscopic controls were only used in this first clinical trial to make sure that the probe hook was in the correct position. In the future, fluoroscopic controls will not be needed at all.

Regarding financial resources in trauma care, introducing a new navigation system is always associated with acquisition costs. Benefits for all stakeholders have to be

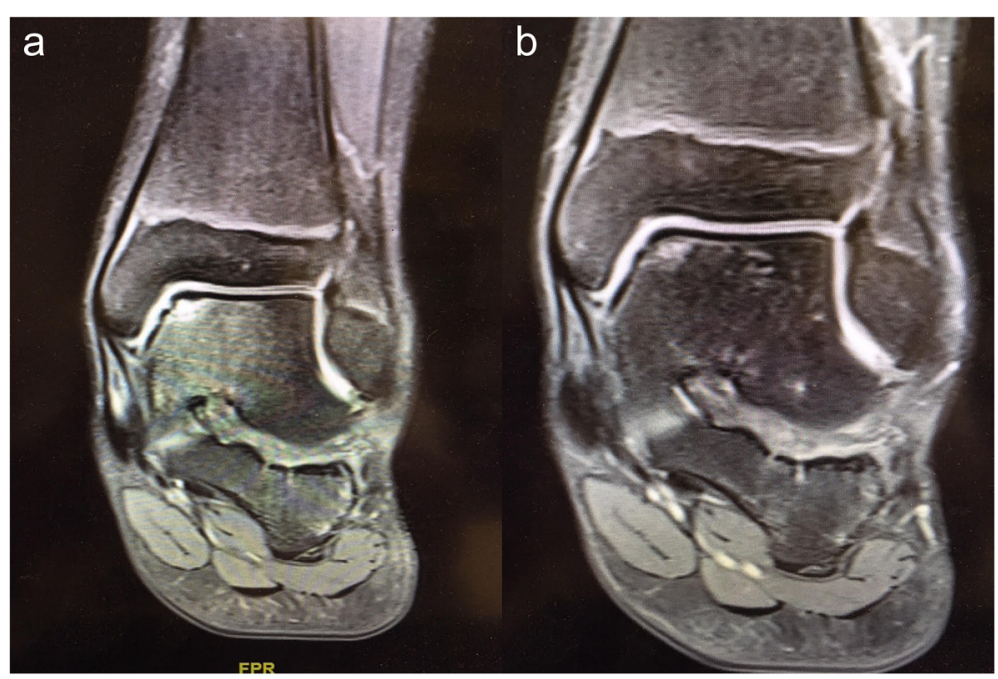

Fig. 4 a/b MRI preoperatively (a) and 12 months postoperatively (b) in a 12 year old boy treated with retrograde drilling via electromagnetical guidance 
clear and visible [33]. However, length of surgery is an expense factor and a significant reduction leads to an increased cost-effectiveness overall as well as to lower infection rates.

The novel ENS method provided a time benefit of approximately $16 \mathrm{~min}$, which represents $>50 \%$ of total operation time compared to the SFF method and a reduction in radiation exposure of approximately $40 \mathrm{mSv}$ per procedure.

Drilling of an OCD lesion of the distal femur has shown to have complete bone healing in up to $90 \%$ of patients on an average after 6 months postoperatively [34]. Comparative literature for the talus is lacking. In a case series of six patients, Mosquijo et al. observed a relief of symptoms in all patients, but only three patients (50\%) showed complete healing on radiographs on a mean follow-up of 37 months [32]. Our clinical experience manifests a slow but continuous healing process of talar OCD lesions on follow-up MRIs.

\section{Limitations}

Limitations of this study are the absence of power analysis and the low sample size in our single center study. While the precision of the drilling with the ENS method was well documented in previous cadaver studies. [16, 23-25] Our study focusses on the comparison of two operation methods and with this study design no conclusions can be made about precision of the drillings.

\section{Conclusions}

In conclusion, the ENS method used in this study led to a reduction in length of surgery and required less $\mathrm{x}$-ray radiation compared to the standard fluoroscopic technique. Cartilage perforation did not occur with this technique.

\section{Acknowledgements}

Not applicable.

\section{Authors' contributions}

ODJ: Conception and design, performed measurements, drafting of manuscript. JBG: Acquisition and data, performed measurements, analysis and interpretation of data, corresponding author. $\mathrm{MH}$ : technical support, drafting of manuscript. MS: statistical analysis, critical revision. KLK: language editing, critical revision, technical support. RS: Conception of study, critical revision of manuscript. MR: administrative, technical and material support, analysis and interpretation of data, supervision. The authors read and approved the final manuscript.

\section{Funding}

This research did not receive any specific grant from funding agencies in the public, commercial, or not-for-profit sectors. Open Access funding enabled and organized by Projekt DEAL.

\section{Availability of data and materials}

The datasets used and analyzed during the current study are available from ODJ on reasonable request.

\section{Ethics approval and consent of participate}

All procedures performed involving human participants were in accordance with the ethical standards of the institutional review board (Ethik-
Kommission der Ärtzekammer Hamburg) resolution (reference number: WF 085/20) and with the 1964 Helsinki Declaration and its later amendments. Informed consent was signed by all patients/parents.

\section{Consent for publication}

Not applicable.

\section{Competing interests}

The authors declare that they have no competing interests.

\section{Author details}

${ }^{1}$ Department of Pediatric Orthopedics, Altonaer Children's Hospital, Bleickenallee 38, 22763 Hamburg, Germany. ${ }^{2}$ Department of Trauma and Orthopaedic Surgery, University Medical Center Hamburg-Eppendorf, Martinistr. 52, 20246 Hamburg, Germany. ${ }^{3}$ Department of Trauma-, Orthopaedic Surgery and Sports Medicine, Asklepios Hospital St. Georg , Lohmühlenstr. 5, 20099 Hamburg, Germany.

Received: 9 October 2020 Accepted: 24 January 2021

Published online: 03 February 2021

\section{References}

1. Wu M, Fallon R, Heyworth BE. Overuse Injuries in the Pediatric Population. Sports Med Arthrosc. 2016;24:150-8.https://doi.org/10.1097/JSA. 0000000000000129.

2. Kessler JI, Jacobs JC, Cannamela PC, Shea KG, Weiss JM. Childhood obesity is associated with osteochondritis dissecans of the knee, ankle, and elbow in children and adolescents. J Pediatr Orthop. 2018;38:e296-9. https://doi. org/10.1097/BPO.0000000000001158.

3. Chabanova E, Larsen L, Løgager VB, Møller JM, Thomsen HS. Use of magnetic resonance imaging. Ugeskr Laeger. 2014;176:50-4.

4. Kessler JI, Weiss JM, Nikizad H, Gyurdzhyan S, Jacobs JC, Bebchuk JD, et al. Osteochondritis dissecans of the ankle in children and adolescents: demographics and epidemiology. Am J Sports Med. 2014;42:2165-71. https://doi.org/10.1177/0363546514538406.

5. Steman JAH, Dahmen J, Lambers KTA, Kerkhoffs GMMJ. Return to sports after surgical treatment of osteochondral defects of the talus: A systematic review of 2347 cases. Orthop J Sport Med. 2019;7:2325967119876238. https://doi.org/10.1177/2325967119876238.

6. Vannini F, Cavallo M, Baldassarri M, Castagnini F, Olivieri A, Ferranti E, et al. Treatment of juvenile osteochondritis dissecans of the talus: current concepts review. Joints. 2015;2:188-91 http://www.ncbi.nlm.nih.gov/ pubmed/25750908.

7. Fraissler L, Boelch SP, Schäfer T, Walcher M, Arnholdt J, Maier G, et al. Vitamin $D$ deficiency in patients with idiopathic and traumatic osteochondritis dissecans of the talus. Foot ankle Int. 2019:40:1309-18. https://doi.org/10.1177/1071100719864325.

8. Anders S, Götz J, Grifka J, Baier C. [Ankle cartilage repair: Therapeutic options, results and technical aspects]. Orthopade. 2017;46:938-46. https:// doi.org/10.1007/s00132-017-3470-y.

9. Laffenêtre O. Osteochondral lesions of the talus: Current concept. Orthop Traumatol Surg Res. 2010;96:554-66.https://doi.org/10.1016/.otsr.2010.06.001.

10. O'Loughlin PF, Heyworth BE, Kennedy JG. Current concepts in the diagnosis and treatment of osteochondral lesions of the ankle. Am J Sports Med. 2010;38:392-404.https://doi.org/10.1177/0363546509336336.

11. Richter M, Zech S. [Navigated retrograde drilling in Osteochondrosis dissecans (OCD) of the talus]. Oper Orthop Traumatol. 2011;23:473-82. https://doi.org/10.1007/s00064-010-9005-x.

12. Takao M, Ochi M, Naito K, Uchio Y, Kono T, Oae K. Arthroscopic drilling for chondral, subchondral, and combined chondral-subchondral lesions of the talar dome. Arthroscopy. 2003;19:524-30. https://doi.org/10.1053/jars.2003.50111.

13. Taranow WS, Bisignani GA, Towers JD, Conti SF. Retrograde drilling of osteochondral lesions of the medial talar dome. Foot ankle Int. 1999;20:47480.https://doi.org/10.1177/107110079902000802.

14. Aurich M, Albrecht $D$, Angele P, Becher C, Fickert S, Fritz J, et al. Treatment of osteochondral lesions in the ankle: A guideline from the Group "Clinical Tissue Regeneration" of the German Society of Orthopaedics and Traumatology (DGOU). Z Orthop Unfall. 2017;155:92-9. https://doi.org/10. 1055/s-0042-116330

15. Goebel S, Steinert A, Rucker A, Rudert M, Barthel T. Minimally invasive retrograde drilling of osteochondral lesions of the femur using an 
arthroscopic drill guide. Oper Orthop Traumatol. 2011;23(2):111-20. https:// doi.org/10.1007/s00064-011-0014-1.

16. Hoffmann M, Schroeder M, Rueger JM. A novel computer navigation system for retrograde drilling of osteochondral lesions. Sports Med Arthrosc. 2014; 22:215-8.https://doi.org/10.1097/JSA.0000000000000036.

17. Bale RJ, Hoser C, Rosenberger R, Rieger M, Benedetto KP, Fink C. Osteochondral lesions of the talus: computer-assisted retrograde drillingfeasibility and accuracy in initial experiences. Radiology. 2001;218:278-82. https://doi.org/10.1148/radiology.218.1.r01ja18278.

18. Seebauer CJ, Bail HJ, Wichlas F, Jung T, Papanikolaou IS, van der Voort I, et al. Osteochondral lesions of the talus: retrograde drilling with high-fieldstrength MR guidance. Radiology. 2009;252:857-64. https://doi.org/10.1148/ radiol.2523081981.

19. Ojala R, Kerimaa P, Lakovaara M, Hyvönen P, Lehenkari P, Tervonen O, et al. MRIguided percutaneous retrograde drilling of osteochondritis dissecans of the knee. Skeletal Radiol. 2011;40:765-70. https://doi.org/10.1007/s00256-011-1118-2.

20. Berná-Serna JD, Martinez F, Reus M, Berná-Mestre JD. Osteochondritis dissecans of the knee: sonographically guided percutaneous drilling. J Ultrasound Med. 2008;27: 255-9.http:/www.ncbi.nlm.nih.gov/pubmed/18204016

21. Gras F, Marintschev I, Kahler DM, Klos K, Mückley T, Hofmann GO. Fluoro-Free navigated retrograde drilling of osteochondral lesions. Knee Surg Sports Traumatol Arthrosc. 2011;19:55-9. https://doi.org/10.1007/s00167-010-1260-8.

22. Citak M, Kendoff $D$, Kfuri M, Pearle A, Krettek C, Hüfner T. Accuracy analysis of Iso-C3D versus fluoroscopy-based navigated retrograde drilling of osteochondral lesions: a pilot study. J Bone Joint Surg Br. 2007;89:323-6. https://doi.org/10.1302/0301-620X.89B3.18424

23. Hoffmann M, Petersen JP, Schröder M, Spiro AS, Kammal M, Rueger JM, et al. Retrograde drilling of talar osteochondritis dissecans lesions: a feasibility and accuracy analysis of a novel electromagnetic navigation method versus a standard fluoroscopic method. Arthroscopy. 2012;28:154754. https://doi.org/10.1016/j.arthro.2012.03.003.

24. Hoffmann M, Hartel M, Schroeder M, Reinsch O, Spiro AS, Ruecker AH, et al. Electromagnetic navigation provides high accuracy for transcoracoidtransclavicular drilling. Knee Surg Sports Traumatol Arthrosc. 2014;22:223742. https://doi.org/10.1007/s00167-013-2607-8.

25. Hoffmann M, Petersen JP, Schröder M, Hartel M, Kammal M, Rueger JM, et al. Accuracy analysis of a novel electromagnetic navigation procedure versus a standard fluoroscopic method for retrograde drilling of osteochondritis dissecans lesions of the knee. Am J Sports Med. 2012;40: 920-6. https://doi.org/10.1177/0363546511434407.

26. Hepple S, Winson IG, Glew D. Osteochondral lesions of the talus: a revised classification. Foot ankle Int. 1999;20:789-93. https://doi.org/10.1177/ 107110079902001206.

27. No Title. https://cartilage.org/content/uploads/2014/10//CRS_evaluation.pdf.

28. Brittberg M, Winalski CS. Evaluation of cartilage injuries and repair. J Bone Joint Surg Am. 2003;85-A Suppl:58-69.https://doi.org/10.2106/00004623200300002-00008.

29. Cohen J. A coefficient of agreement for nominal scales. Educ Psychol Meas. 1960;20:37-46. https://doi.org/10.1177/001316446002000104.

30. Gras F, Marintschev I, Müller M, Klos K, Lindner R, Mückley T, et al. Arthroscopiccontrolled navigation for retrograde drilling of osteochondral lesions of the talus. Foot Ankle Int. 2010;31:897-904. https://doi.org/10.3113/FAl.2010.0897.

31. Kreuz PC, Steinwachs M, Edlich M, Kaiser T, Kaiser T, Mika J, et al. The anterior approach for the treatment of posterior osteochondral lesions of the talus: comparison of different surgical techniques. Arch Orthop Trauma Surg. 2006;126:241-6. https://doi.org/10.1007/s00402-005-0058-5.

32. Masquijo JJ, Ferreyra A, Baroni E. Arthroscopic retrograde drilling in juvenile osteochondritis dissecans of the talus. J Pediatr Orthop. 2016;36:589-93. https://doi.org/10.1097/BPO.0000000000000498.

33. Hoffmann M, Reinsch OD, Petersen JP, Schröder M, Priemel M, Spiro AS, et al. Percutaneous antegrade scaphoid screw placement: a feasibility and accuracy analysis of a novel electromagnetic navigation technique versus a standard fluoroscopic method. Int J Med Robot. 2015;11:52-7. https://doi. org/10.1002/rcs.1572.

34. Masquijo J, Kothari A. Juvenile osteochondritis dissecans (JOCD) of the knee: current concepts review. EFORT open Rev. 2019;4:201-12. https://doi.org/10. 1302/2058-5241.4.180079.

\section{Publisher's Note}

Springer Nature remains neutral with regard to jurisdictional claims in published maps and institutional affiliations.

Ready to submit your research? Choose BMC and benefit from:

- fast, convenient online submission

- thorough peer review by experienced researchers in your field

- rapid publication on acceptance

- support for research data, including large and complex data types

- gold Open Access which fosters wider collaboration and increased citations

- maximum visibility for your research: over $100 \mathrm{M}$ website views per year

At BMC, research is always in progress.

Learn more biomedcentral.com/submissions 